\title{
Un reto para las publicaciones científicas en Colombia
}

Ante el anuncio de un nuevo modelo propuesto por Colciencias para la indexación de revistas colombianas en 2016, las instituciones se vieron en la necesidad de iniciar un proceso de ajuste en las políticas editoriales con base en parámetros de medición que hasta ese momento no constituían información oficial y sin la garantía de tener un periodo de transición para acoger los lineamientos; a fin de que sus revistas continuaran indexadas por el IBN - Publindex de Colciencias.

Como se avizoraba, muchas revistas no cumplieron con los requisitos mínimos debido a varios factores que enmarcan el contexto de la labor editorial de la publicaciones científicas, entre ellos, los costos que implica dicha labor, la mínima cantidad de horas semanales que se asigna al editor para esta función, la exigencia de que las revistas estén incluidas en diversas bases de datos del conocimiento, como una estrategia para incrementar su visibilidad ante la comunidad científica internacional, la imperante necesidad de publicar en un segundo idioma, entre otros, constituyeron la antesala de argumentos para que más del 50\% de las revistas en el país perdieran la indexación; que más que una categoría, representa el esfuerzo de equipos editoriales por mantener vivo un proyecto que nació con el propósito de publicar resultados de investigación científica en áreas específicas del conocimiento.

La Revista Universidad y Salud surgió en el año 2000 como un medio de publicación de los trabajos de investigación de postgrados en salud que ofrecía en ese entonces el Centro de Estudios en Salud de la Universidad de Nariño - CESUN. En estos diecisiete años, la Revista se ha enfrentado a diversos cambios y retos que le han permitido no sólo mantenerse, sino avanzar progresivamente hacia los estándares internacionales; como el paso de publicación impresa a on-line, la periodicidad cuatrimestral, el cautivar tanto a autores como evaluadores colombianos y de países como Chile, Ecuador, Argentina, Brasil, Venezuela, Costa Rica, Cuba y España a participar en el proceso, y el sometimiento a la evaluación en rigurosas bases de datos como Lilac's, SciELO, DOAJ y Redib en las cuales ha sido aceptada. A partir de septiembre de 2017 la Revista quedó indexada en categoría C por el IBN-Publindex, lo cual evidencia el compromiso del equipo, de los autores y evaluadores, así como de la visión de la directora del CESUN, la Magister María Clara Yépez Chamorro, quien con su conocimiento y apoyo ha orientado el proceso desde su creación.

Esta indexación es la oportunidad para continuar haciendo todos los ajustes a que haya lugar para lograr ascender en la clasificación de Publindex y ser reconocida internacionalmente. En este momento la Revista se encuentra en el proceso de evaluación en las bases de Redalyc y Scopus, se postulará a Pubmed y Scopus y dará inicio a la recepción y publicación de artículos en inglés. Asimismo, es importante agradecer a todos aquellos colaboradores que reconocen este trabajo y están dispuestos a contribuir en el cumplimiento de los nuevos retos que demanda el mundo de las publicaciones científicas.

Esp. Mónica Alejandra Enríquez García

Editora invitada

Profesional Centro de Estudios en Salud - CESUN

Universidad de Nariño

Pasto, Colombia 